\title{
Participation of Women for the Development of Civil Society: A Study among Women Representatives in Local Governance
}

Raheena P A* and Sara Neena $\mathrm{T} \mathrm{T}^{\dagger}$

\section{Abstract}

Political Participation and grass root democracy have been strengthened considerably by the 73rd and 74th Constitutional Amendments that have created new democratic institutions for local governance by giving the opportunity to women in the local administration. Indian Government raised reservation for women in all tiers of the panchayat raj system from 33 to 50 percent. An elected women representative needs the requisite social space in order to effect and experience the changes that she desires. The involvement of women in the development process is not merely a matter of equality but a necessity too. This study attempted to assess the involvement of women representatives to the development of weaker sections of society, especially women and children. This study was conducted in village panchayats under Cherpu and Ollukkara blocks in Thrissur district. Simple random sampling technique was adopted for selecting the sample of fifty elected women representatives and data collected through structured Questionnaire Method.

Keywords: Women Representatives, Local Governance, Civil Society, Good governance, Political empowerment

\footnotetext{
*St.Teresa's College, Ernakulam, Kerala, India; rahi.tsr@gmail.com † Vimala College, Thrissur, Kerala, India; sneej11@gmail.com
} 


\section{Introduction}

The73rd amendment was introduced as a strategy to empower women by giving them the opportunity to participate in the decision making the process at the grassroots level. Political empowerment of women and their active participation in local selfgovernance bodies should not be based on "luck" factor. This massive participation of women in local governance allowed them not only to enter intopolitics but gave them a greater presence within the public life. The political participation in local governance helps the women to bring about change in the society.

Constitutional efforts are helpful to strengthen and consolidate them for meaningful empowerment. The question is whether an intervention like the constitutional amendment can ensure women's empowerment or whether the patriarchal structures, manifested in the household and the state, will continue to dominate. Recent legislative measures have made possible the greater participation of women in local government. However, there are structural and other constraints which keep women from actively participating in the administration (Manu Bhaskar, 1997).

Political participation is one of the major ways to ensure women's empowerment, to increase decision-making power and greater ability and to influence matters that affect their lives in the community and the larger society. In the broader sense, participation in politics goes far beyond electoral politics, such as voting and election to public office. Women's empowerment begins with their consciousness - perceptions about herself and her rights, her capabilities and her potentials, awareness of her gender and socio-cultural, economic and political forces that affect her (Reema Mukherjee, 2008).

Gender empowerment is determined by the degree to which women and men participate actively in economic, professional and political activity and take part in decision-making. Women's political participation was hindered by a system of social relations in the male-dominated society, reflecting the orthodox male-centric mentality and religious fundamentalism. Only men were consistently educated and trained for leadership, while very few rural women had the opportunity to pursue their education 
because of tradition. Gender Empowerment is essential for the sustainable development of a nation. Women force in a country should transform into an active human resource. For the family, society and country to have a bright future it imperative that the women are empowered. Pandit Jawaharlal Nehru had said that "to awaken the people, we should first awaken the women, because once a woman has been awakened then the whole nation and family gets awakened with her".

Reserved seats or affirmative action to ensure women's political representation is an important step in democratising and engendering local governance. However, the mere presence of women does not guarantee the quality or effectiveness of their participation, that their voices will be heard in critical decisions, or that concerns of women electorates will automatically be championed. Many women elected to local government on reserved quotas are new to the public sphere of politics, inexperienced with governance institutions, and unfamiliar with procedures and protocols of formal meetings. Anne Philip (1995) analysed distinction between the politics of ideas and the politics of presence. The politics of ideas considers accountability in relation to declared policies and programs and sees the sex or race of the representative as a matter of relative indifference. In the politics of presence, by contrast, the gender or ethnic composition of elected assemblies becomes a legitimate matter of democratic concern.

Mahatma Gandhi also believed that full and balanced development of the nation and establishment of a just society is possible only when women participate actively and fully in the political deliberations of the nation. The Balwant Rai Mehta Committee on Panchayati Raj System emphasised that rural women should not become mere beneficiaries of development but should be made equal partners in its affairs as contributors.

Discriminatory practices, social norms, and cultural perceptions that women are not well suited for leadership and decision-making positions, combined with family and child-care responsibilities, discourage and limit women's involvement in politics. Women's limited participation in political decision making acts as a barrier to making policy and service delivery more responsive to women's needs and more accountable to women. It is now widely 
recognized that women's representation and voices in decisionmaking bodies-as leaders and participants-can contribute to changes in laws, policies, service delivery, cultural perceptions, and social norms.

Elected women representatives emphasise priorities that are different from men members, although these priorities largely remain within the framework of development (i.e., access to basic amenities and infrastructure). Such priorities at best serve women's practical gender needs and not their strategic gender interests. Practical gender needs are immediate perceived needs identified by women such as water and healthcare, which fall within their socially defined roles. Meeting these needs does not necessarily involve challenging women's status in society or a focus on gender equity. It approaches to transform gender relations and change women's position in society rather than only improve their condition.

Itis commonly believed that women representatives are more approachable and that the problems of women, in particular, are now being addressed. "Once women came into office, other women would open up to them." Women excel in dealing with grassroots issues within the community compared to men who do not see it as important to concentrate on domestic and women problems. Any social evils directly affect women and children first.

Personal and work-related challenges can influence women's capacity to carry out their public responsibilities as elected officials. Personal challenges can include a low level of education, lack of support from husband and family members, lack of confidence, and role conflicts while managing both household and public life. Critical work-related challenges include lack of knowledge and understanding about their role as elected officials, navigating the operational procedures, limited facilitation and advocacy skills, lack of information about meeting procedures and protocols, and lack of support from male colleagues.

Gender analysis includes information on women and men, girls and boys in terms of division of labour, roles and responsibilities, access to and control over resources, and their relative condition and position in society. It also involves looking at other norms for 
how gender may be expressed, including norms relating to sexuality and identity (Swedish International Development Cooperation Agency, March 2015) Gender budgeting is a tool which can be used to aid women's empowerment. In order to do this, the government is addressing gender issues through public expenditure. It must ensure it allocates certain amount of the government's budget to male, female and children to ensure gender equality.

Women's participation feminises politics rather than be a part of men's stream. Gandhi played an important role in motivating women in participate in the freedom movement and political process. He saw women as a potential force in the struggle to build a new social and political order. Gandhi quoted that "If nonviolence is the law of our being, the future is with women".

Female reservation quotas have led to increasing the numbers of women representatives in local government bodies, these women require capacity development, leadership skills, and strategic support to fully exercise their power and truly represent the constituency they serve.

'Family Consent" is a factor crucial for their Political participation. Women are also allowed to participate when their men are involved in a struggle. The $73^{\text {rd }}$ Amendment was introduced as a strategy to empower women by giving them the opportunity to participate in the decision making process at the grassroots level. There is a great need for the community to participate more meaningfully in the governance process and also for the institutions to have spaces for economic planning.

\section{Political Participation of Women in India}

The root to the participation of women in politics can be traced back to 19th-century reform movement. The early 19th-century social reforms and educational programmes initiated by various social reformers dealt with the social evils prevalent in the society.

As early as 1917 Indian women raised the issue of representation in politics, which at a time meant a demand for the universal adult franchise. Post independence, women continued to play a significant role in less conventional political activities such as 
environmental movements, peace movement, anti-alcohol movement, which equally affect power relationships as they have the capacity to influence the state. Politics proved to be an inhospitable terrain for women and continues to be male dominant. The Government of India has declared the year 2001 as the year of empowerment of women.

The Indian government has raised reservations for women in all tiers of Panchayati Raj system from 33 to 50\%.The Union Cabinet presided over by Prime Minister Manmohan Singh, cleared a proposal to amend Article 243(D) of the constitution for this purpose on August 27,2009.The median citizen in most democracies is female, and that the interests of women traditionally have beenunderrepresented, it is reasonable to expect that women's interests should reflect government policy and procedures(Hanna Pitkin,1967). With an aim to overcome issues of discrimination and violence, women's organisations have focused on the empowerment of Indian women. Empowerment is tied to the support of family and improved status within the household. However, it is undermined by the threat of so manySocio-economic conditions.Inability to understand the rules of Panchayat Raj undermines the self-confidence of women to participate in public office (Prayaga Rai, 2014)

\section{Women in Local Self-governance - Kerala}

Kerala has a high percentage of highly qualified or educated women and yet there is relatively space for women leadership and empowered roles and fewer articulate voices in public and private life. Fifty percent reservation for women in local bodies has enabled women representatives to have an impact on bringing forth positive and qualitative changes within Kerala Society. Efforts to mainstream women in politics must be a continuous process. Kerala experience shows that in-depth and continuous capacity development programs targeting elected women representatives should accompany their affirmative action. The rapidly changing scenario seems to have important implications for gendering governance in Kerala.

They are welcoming women into office. But still, they face several hurdles and anti-woman customs, interference from party 
politicians and other male counterparts, backseat driving, inexperience and having no direct relation to society. Women can only go for this role when they have family support. It not like other jobs. More active social life increases general awareness and confidence in them. (Radha. S and Bulu Roy Chowdhury, 2002)

The potentials of local government institutions can be realised more effectively where there aredecentralisation and devolution of powers. Accountability, transparency, participation, empowerment, equity and all other attributes of good governance can be in full play and become a part of the daily work of both the government and local government bodies when decentralisation and devolution take place. Women's enhanced participation in governance structures is viewed as the key to redress gender inequalities in societies. One of the important reasons why women have not received adequate benefits from years of planning and development was their inadequate representation, nonparticipation and non-involvement in the preparation and execution of plans for their economic development and social justice through decentralised institution (Shamim Ishrat and Kumari Ranjana, 2002)

Swetha (2008) in her work on "situating Indian Women" argues that no political party wants the risk of fielding a 'housewife' who is neither seasoned nor mentally prepared for a hectic political life. In comparison to men, the "win-ability" factor is very much low in case of women candidates. It is commonly believed that women do not succeed in winning a seat except when they carry the banner of some popular male figure.

G. Palanithurai and Asokkumar Mittal (2004) in their work 'Dynamics of New Panchayathi Raj System in India empowering Women" explains the positive indicators of women's participation as the experiences of Kerala shows that attempts to bring about effective and good governance. If good governance is about equity and equality, gender and gender equity has to be major concerns in development. The final control over resources and the decisionmaking capacity is still with men. Kerala has taken a step in the right direction, but it needs conscious intervention to progress further. 


\section{Public-Private Domain Theory}

Vicky Randall (1987) observes ideologically to justify women's exclusion from public politics while women's actual confinement to narrow domestic areas has been major break upon effective political participation. Public-private convention has masked the crucial interdependence of these spheres. Not only women's private roles but public policies have confirmed their private obligations.

\section{Significance of the Study}

The $73^{\text {rd }}$ and $74^{\text {th }}$ Constitutional Amendment Acts provide an opportunity for women's entry into political spheres. The 73 rd Constitutional Amendment Act is an important landmark in the history of Indian women's participation in the formation of democratic institutions at the grassroots level. The reservation in Panchayats has provided for the erosion of the traditional gender, caste, class roles and hierarchy but it is a long and difficult process. Women not only have to fight for their right to be more than proxy members but also to break the many other barriers. There can be no real progress if women of a country are not made partners in this process of development. Women's political empowerment and equal representation in all decision-making institutions are critical inputs in their struggle for freedom from patriarchal subjugation.

\section{Objectives}

1. To analyse the socio-economic and political profile of women representatives in local governance.

2. To assess the involvement of women members in the development process.

3. To evaluate the role of women representatives in addressing the needs and issues related to women, children and weaker sections

4. To find out the problems and challenges faced by these women group.

This study descriptively focused on women representatives in different Grama Panchayaths under Cherpu and Ollukkara blocks 
in Thrissur District. The study analyses the role of women members in the local development and upliftment of weaker sections. The study also focuses on challenges faced by them.

Fifty women elected representatives for the period 2010-2015 formed the sample population for the study. Samples were selected through simple random sampling method.

\section{Findings}

\section{Socio-Economic and Political Profile}

The mean age of the respondents is 39.This finding was supported by the study conducted by Manikyamaba (1996) in Andhra Pradesh observed that the extent of participation of the young and the middle age is more than that of old age. Seventy percent of them completed S.S.L.C. Seven out of ten were Hindus. A great majority $(83 \%)$ were from the nuclear family set-up. Eighty percent of them were from middle-class families. Nine out of ten expressed that their husbands are the biggest support for their political activities. More than three-fourths opined that children are also giving moral support to them, while ten percent revealed that their children were not cooperating to perform their role as a member. More than sixty percent of them have no prior political experience.

The use of electoral gender quotas challenges our ideas and theories about the relationship between women's political representation and their socio-economic position, since quotas may lead to unprecedented historical leaps in women's socio-economic positions (Dahlerup, 2006). Shvedova (2005) opined that socioeconomic environments play a substantial role in women's political Participation. The social and economic status of women in society has a direct influence on their participation in political institutions and elected bodies.

\section{Participation in Local Development}

In this study, seventy percent expressed that their wish to involve in village development motivated them to contest in elections. Ten percent contested the election due to non-availability of women candidates. More than eighty percent are active in frequent local visit and spend most of the time for panchayath activities. More 
than ninety percent are accurate in attending Panchayath committee meetings.

Table 1 Involvement in different decision-making areas.

\begin{tabular}{lllllr}
\hline Sl.No & \multicolumn{1}{c}{ Area } & High & Medium & Low & Total \\
\hline 1. & $\begin{array}{l}\text { Employment } \\
\text { assistance }\end{array}$ & $8(16)$ & $12(24)$ & $30(60)$ & $50(100)$ \\
2. & $\begin{array}{l}\text { Basic needs(house, } \\
\text { water, toilet) }\end{array}$ & $39(78)$ & $11(22)$ & - & $50(100)$ \\
& Infrastructure & $21(42)$ & $19(38)$ & $10(20)$ & $50(100)$ \\
\hline
\end{tabular}

The above table shows women members could contribute more to the fulfilment of basic needs (house, house up gradation, drinking water, sanitation facilities etc.) of local people. The great majority of (78) the respondents have taken an active role in fulfilling the basic needs of the local people. Nearly one fifth (16) play a significant role in providing employment opportunities to the public.

In this study, less than half (43) opined that they got very fewer chances to express their ideas and thoughts in major decisionmaking process. Seventy percent (70) revealed that there was only partial acceptance of their statements and demands. More than half percent of them argued that the tag as "women" worked as a barrier for the opinion to be accepted.

Table 2 Various Obstacles in the process of policy implementation

\begin{tabular}{llcrrc}
\hline S1.No & \multicolumn{1}{c}{ Obstacles } & Agree & Neutral & Disagree & Total \\
\hline 1. & $\begin{array}{l}\text { Lack of sufficient } \\
\text { fund }\end{array}$ & $25(50)$ & $12(24)$ & $13(26)$ & $50(100)$ \\
2. & $\begin{array}{l}\text { Non-cooperation } \\
\text { from officials and } \\
\text { opposition }\end{array}$ & $13(26)$ & $12(24)$ & $25(50)$ & $50(100)$ \\
3 & $\begin{array}{l}\text { Lack of awareness } \\
\text { and coordination } \\
\text { Corruption }\end{array}$ & $18(36)$ & $14(28)$ & $18(36)$ & $50(100)$ \\
4 & $11(22)$ & $15(30)$ & $24(48)$ & $50(100)$ \\
\hline
\end{tabular}

Half of them opined that lack of sufficient fund makes problems in implementing projects. 
Nearly forty percent of the sample population expressed that lack of awareness about the system and coordination of activities are the main hurdles while implementing developmental projects.

The concept of women empowerment refers to giving women maximum participation in decision-making process and powersharing in the representative bodies, employment, access to property, productive assets, common land and financial assets etc.(Hatim,2001)

\section{Upliftment of women, children and weaker sections}

The presence and participation of women in local governance structures also does not guarantee that the issues of women are concerned about and those that underlie social injustices will be taken up and addressed by PRIs

The study found out that seventy-six percent agreed that they worked for the upliftment of the socially-economically weaker sections of the society (SC, Minority, BPL families, Widows etc.). Only six percent could contribute to the child development activities. More than sixty percent expressed that most of the women in their area suffer from economic problems. Many of the women in their areas do not have proper housing and other related facilities.

More than eighty percent agreed that PRI and Kudumbasree play a vital role in building leadership qualities and self-confidence in the women of rural areas. A good proportion of them agreed that women in public life need to have special skills to analyse budgetary provision in favour of empowerment of women. Most of them said that economic backwardness is the main issue that hits the lives of women in their locality. A great majority are not satisfied with their own performance in child welfare schemes. 
Table 3 Problems faced by Women and children in their locality

\begin{tabular}{llrrrr}
\hline Sl.No & $\begin{array}{l}\text { Problems of women } \\
\text { and children }\end{array}$ & $\begin{array}{c}\text { High } \\
\text { level }\end{array}$ & $\begin{array}{c}\text { Medium } \\
\text { level }\end{array}$ & $\begin{array}{r}\text { Low } \\
\text { level }\end{array}$ & Total \\
\hline 1 & Nutrition for children & $20(40 \%)$ & $25(50 \%)$ & $5(10)$ & $50(100)$ \\
2. & Ill-health of women & $20(40 \%)$ & $19(38 \%)$ & $11(22 \%)$ & $50(100)$ \\
3 & $\begin{array}{l}\text { Maternity related } \\
\text { issues }\end{array}$ & $7(14 \%)$ & $15(30 \%)$ & $28(56 \%)$ & $50(100)$ \\
4 & Infantmortality & - & $9(18 \%)$ & $41(82 \%)$ & $50(100)$ \\
5 & $\begin{array}{l}\text { Sexual attack on } \\
\text { women and children }\end{array}$ & $15(30 \%)$ & $13(26 \%)$ & $22(44 \%)$ & $50(100)$ \\
6 & $\begin{array}{l}\text { Alchaholism of male } \\
\text { bread winners }\end{array}$ & $17(34 \%)$ & $23(46 \%)$ & $10(20 \%)$ & $50(100)$ \\
7 & Dowry related issues & $17(34 \%)$ & $22(44 \%)$ & $11(22 \%)$ & $50(100)$ \\
\hline
\end{tabular}

Forty percent of them opined that women in their area face health issues due to heavy workload, multitasking, poor economic background and stress etc. But the majority of them said issues related to pregnancy and childbirth are low in their area.

Including women, especially in local governments, is an essential step towards creating gender-equal opportunities and gendersensitive policies. Since women have different needs and perspectives on social and political issues, it is important to involve women in governance to incorporate all of the societal viewpoints in policy and decision-making processes. Women are actively involved in household and community work. Hence they are well aware of real issues faced by common people. This gives them insight and perspective which can be instrumental in overall sustainable development.

Table 4 Distribution of respondents by giving priority to the development oftheir locality

\begin{tabular}{llrrrc}
\hline \multicolumn{1}{c}{ Sl.No } & \multicolumn{1}{c}{ Priority Area } & \multicolumn{1}{c}{ High } & Medium & \multicolumn{1}{c}{ Low } & \multicolumn{1}{c}{ Total } \\
\hline 1. & Welfare of women & $10(20)$ & $35(70)$ & $5(10)$ & $50(100)$ \\
2. & Welfare of children & $12(24)$ & $33(66)$ & $5(10)$ & $50(100)$ \\
3. & Developmental action & $18(36)$ & $29(58)$ & $3(6)$ & $50(100)$ \\
4. & Eradication of social & $8(16)$ & $26(52)$ & $16(32)$ & $50(100)$ \\
& Problems & & & & \\
\hline
\end{tabular}

More than thirty-five percent of them concentrated more in introducing developmental actions. Twenty percent (20) worked for the improvements in the livelihood of women in their localities. 
A little more than twenty (24) worked for the welfare of children and a small proportion involved themselves in the eradication of various social problems.

\section{Problems and challenges}

Table5 Issues Faced by the Respondents

\begin{tabular}{|c|c|c|c|c|c|}
\hline Sl.No & Problems & Always & Sometimes & Never & Total \\
\hline 1. & $\begin{array}{l}\text { Opposition from } \\
\text { family and } \\
\text { community }\end{array}$ & $12(24)$ & $30(60)$ & $8(16)$ & $50(100)$ \\
\hline 2. & Lack of awareness & $16(32)$ & $23(46)$ & $11(22)$ & $50(100)$ \\
\hline 3. & Discrimination & $14(28)$ & $21(42)$ & $15(30)$ & $50(100)$ \\
\hline 4. & $\begin{array}{l}\text { Lack of support and } \\
\text { security }\end{array}$ & $14(28)$ & $13(26)$ & $23(46)$ & $50(100)$ \\
\hline
\end{tabular}

More than twenty-five percent always felt that gender discrimination (may be called as positive) is the main challenge in their political participation. More than thirty percent of them (32) opined that lack of awareness is the major issue in their performance. Six out of ten agreed that in the early stage of their career as a public servant they had communication problems. Nearly two-thirds of them expressed that honorarium is not sufficient to carry out their duties and to meet their expenses related to public affairs.

A great majority (86) of them agreed that training is very much needed to representatives especially who entered local government for the first time. Forty percent were of the opinion that there is a tendency to assassinate the character of women members. Thirty percent of the women representatives were not able to participate properly owing to the heavy workload and lack of support from family. Farzana Bari (2005) in her study reported that with their primary roles as mothers and wives and competing for domestic responsibilities and care work, women are left with little time to participate in politics.

\section{Major Findings}

A great majority of women members were from middle-class families. Most of them were living in the nuclear family set-up. Family support is very essential for performing their political role. 
Most of the women representatives came to the position with a vision of developing their respective areas. A great majority of them actively participate in their respective political position. A considerable proportion gives attention to the fulfilment of basic needs of their wards. Nearly half of the population expresses their anxiety in the partial acceptance of their views and lack of opportunity in the discussions. They felt discrimination in administrative and decision-making spheres. Half of the sample group agreed that lack of awareness and poor coordination stand as a barrier for the developmental activities. A good proportion could contribute for the betterment of women in weaker sections. But many of them were not satisfied with their performance in child development activities. Most of them work to introduce new developments in their respective wards.

Women members are facing challenges like lack of awareness, role conflict due to multitasking, financial problems, lack of encouragement (Discrimination on gender grounds, character assassination, Lack of support, lack of security, etc.).Women representatives are playing a vital role in addressing strategic gender interests at the local level. The elected women representatives carried a double and triple burden of responsibilities and work covering professional and household spheres. It causes stress and strain. They have to face slander and criticism from families and outsiders. Many of them did not want to contest a second time for this reason. Lack of gender sensitiveness in the implementation machinery is also a challenge to them.

This study reveals that women in local governance have a very significant role, but some socio-cultural factors pull them back from performing to the fullest. The mobility from traditional roles is still a challenge for women. But many of them stand firmly among all odds. The findings of this study are consistent with Benudhar Rout and Sahu (2012) study which concludes that the active participation of women in rural local governance system has remained restricted to a small number of women. The nature and extent of participation of women are limited to a few areas of rural local governance system and not up to the expected extent. The factors that have an impact on their performance are family bonding, 
submissiveness and lack of understanding of their role, and responsibilities. The low level of awareness prevents from active participation in the local rural system.

\section{Conclusion}

Women's entry and effective participation will change the texture of the present day politics and bring women's preferences and perspectives to the political arena. As more women entering to the governing bodies, it is important for all institutions to respond to women's specific needs related to education, gender roles, division of labour etc. Efforts must be made to bring about this transformation in society. Then only the process of women empowerment through political representation becomes meaningful.Women's equal political status and capabilities with men encourage other women to believe this could be a realistic aspiration for them.

\section{References}

Bhaskar, M. (1997). Women panchayat members in Kerala: A profile. Economic and Political Weekly, WS13-WS20.

Bari, F. (2005, November). Women's political participation: Issues and Challenges. In United Nations Division for the Advancement of Women Expert Group Meeting: Enhancing Participation of Women in Development through an Enabling Environment for Achieving Gender Equality and the Advancement of Women. Bangkok.

Dahlerup, D. (Ed.). (2013). Women, quotas and politics. London: Routledge.

Shadima, H. (2001). Empowerment of Women: Problems and Prospects. Indian Journal of Politics, Nos. 1 \& 2, January-June.

Mukherjee, R.(2008).Women in Transition. New Delhi: Adyayan Publications.

Palanithurai, G. (2004).Dynamics of New Panchayati Raj System in India empowering women. (Vol.IV). New Delhi: Concept Publishing Company.

Mishra, S. \& Panda, A.N. (2008),Situating Indian Women. New Delhi: Abhijeeth Publications,

Manikyamba, P. (1996).Women in Panchayat Raj Structures. New Delhi: Ciran Publishing Home.

Phillip, A. (1995). The Politics of Presence, London: Oxford University Press. 
Pitkin, F. H. (1967).The Concept of Representation. Berkeley: University of California.

Randall, V. (1987). Women and Politics: An International Perspective. University of Chicago Press.

Rai, P.(2013). Political Representation and Empowerment: Women in Local Government Institutions in Bihar, India. Sweden: Stockholm University.

Rout, B.\& Sahu, N.T. (2012). Women Participation in Rural Local Self Governance System in Odisha: A Constitutional and ReservationalPerpective. OdishaReview, February-March, 55-65.

Shamim, I., \& Nasreen, M. (2002). Gender and local governance: A new discourse in development. Journal of Social Studies-Dhaka, 50-87.

Shvedova, N.(2005). Obstacles to Women's Participation in Parliament in Ballington. In Julie \& Karam, A. (eds): Women in parliament: Beyond numbers (33).

Radha, S., \& Chowdhury, B. R. (2002). Women in local bodies (No. 40). Centre for Development Studies.

Swedish International Development Cooperation Agency. (March,2015). GenderAnalysis-Principles and elements. 